\title{
Structural Modeling for the Relationship of Organizational Wisdom and Strategic Intelligence
}

\author{
Mohammad Pourdjam A. \\ Educational administration, University of Isfahan, Iran \\ Sayed-Ali Siadat ${ }^{1}$, Ph.D. \\ Associate Professor, Department of Education, University of Isfahan, Iran \\ Saeed Rajaeepour, Ph.D. \\ Associate Professor, Department of Education, University of Isfahan, Iran
}

Received: April 9, 2015 Accepted: March 24, 2015 Published: May 24, 2015

doi:10.5296/jse.v5i2.7407

URL: http://dx.doi.org/10.5296/jse.v5i2.7407

\begin{abstract}
Following the shift from strategic management, there have been signs of a modern approach with the mission of making the management of organizations wise. The present study was done with the purpose of modeling the present situation of the relationship of organizational wisdom and strategic intelligence in the Iranian University of Applied Science and Technology in 2014. This study, based on the typological criteria of research designs, is a compound, uninterrupted multiple phase, qualitative, quantitative start-over study. The research population was the all employees including 591 participants, and a sample size of 236 people was estimated and was selected through stratified random selection based on the size. The instrument for collecting data was a researcher-made questionnaire with 108 items based on 5-point Likert scale. The Cronbach's coefficient was calculated to be 0.93 . And the questionnaire possessed content and construct validity. The collected data was analyzed using the statistical methods of stepwise regressions and path analysis of the structural equation based on the regression coefficients and fitting model indices. The findings showed that based on the researcher-made model using the frequent components in the study literature, organizational wisdom is in a significant relationship with strategic intelligence
\end{abstract}

Keywords: Structural equation modeling, Higher education, Organizational wisdom, Strategic intelligence 


\section{Introduction}

After the industrial and the information era, in the present time, power has its roots in wisdom and consequently the knowledge of management, after adopting something from each of the previous approaches, now is inclining toward wisdom approach. In higher education, having dynamic universities to create knowledge and develop wisdom is a particular opportunity that originates in management and administration. In higher education system administration based on competition, the employees of the university can change the routine way of doing things to an efficient effective process. In the process of finding the best answer, managers see how important wisdom is in the employees and this aspect is more important than their mechanical function. Wisdom is the turning point in higher education the lack of which may lead to complete failure.

This article discusses the wisdom in organizations using the findings from analyzing the existing research body on wisdom, management wisdom and organizational wisdom, and examines its relation with strategic intelligence in the present situation of the University of Applied Science and Technology in order to offer a conceptual model.

\section{Literature review}

Wisdom is related to the understanding and the way of human behavior for which the aspects such as knowledge and intelligence are necessary but not enough for it. It means a person who is not wise can be a scientist or can be intelligent, but wisdom without knowledge and intelligence is meaningless. The nature of wisdom in people is not in what they know or what they are, but in how they keep, use and implement their knowledge. This concept has had a significant value in the survival and development of human communities, but like many other theoretical concepts, it does not enjoy an agreed-upon definition and the cognitive standard base. Kramer (1990) believes a definition of wisdom with which everyone agrees does not exist, thus the systematic study of wisdom appears very difficult. It seems that wisdom is beneficial for workplace, but the fact that an applied definition is hard to achieve has make it challenging for organizations to purposefully employ managers and employees with high levels of wisdom and also to specify a particular value for organizational wisdom in them. It is interesting that for some aspects of wisdom, more is known about the way they combine to form wisdom. The studies conducted in the individual, managerial and organizational level, however limited, have examined wisdom using different measures. Sternberg (1985) reported 6 major components for wisdom; Chandler and Holliday (1990) mentioned 9 groups of components in analyzing the main factors of wisdom. In summarizing the results of Sternberg (1990) with 40 factors and Jason et al (2001) with 38 ones, Reynolds (2003) introduced 20 components for the dimensions of wisdom. Sternberg (1998) believed that human intelligence has increased in the past few generations, but the conflicts and distresses of the present world point out that this intelligence has not yet elevated to the level of wisdom. Also, in organizational dimension, the financial event of large companies such and Enron, WorldCom and Tyco showed that in spite of the development of intelligence in organizations, organizational wisdom has not increased (Delong, 2004). Organizational wisdom pertains to the process of transferring wise knowledge to the human resource and it can be a structural 
concept, with potential value and one of the organizational benefits (Tack, 1986). This evidence emphasizes that there is a close relationship between wisdom and the behavior of the organization.

Organizational intelligence is another important feature in organizations. This concept and the usage of the expression strategic intelligence are quite new, but they got they became popular in managerial concepts and it is used as the key principle of decision making of chief executive officers and the key for efficiency in the process of decision making in strategic management. Strategic intelligence is the synergy of intelligences with knowledge management in the organization and is used to increase efficiency in strategic decision making. Strategic intelligence finds how the organization can be better in challenges and threats and how it can succeed and this is an obligatory part to compete in the modern economy. Libowitz (2011) produced a multi layer model and believes that strategic intelligence is made up of artificial intelligence, knowledge management, business intelligence and competitive intelligence and provides the decision makers in the organization with methods, instruments and models to achieve the organization goals. Different levels of intelligence are related. The first is artificial intelligence, what computers and robots have. It is used to mechanically support the mind power in human and focuses on how to teach and learn, think, explain and decide. Knowledge management is a power based on knowledge and is considered as a part of valuable human assets in organizations, and is a manageable system that has the role of identifying, receiving, sharing, implementing, diffusing and creating knowledge in the organization and thus is strongly related to information and communications technology. Knowledge management includes learning from successful and unsuccessful experiences and past failures. Business intelligence benefits from auditing processes of knowledge. Auditing knowledge reveals a set of non-financial resources of the organization including human, structural and social resources. Competitive intelligence has a close relation with artificial intelligence, business intelligence and knowledge management and like them is compromised of different parts of collection, analysis and management. Competitive intelligence techniques and instruments should include the element of informing and optimizing decision making; without knowing the opponents, environment and other key factors that influence the system and the organization in the future, the possibility of proper decision making declines. Therefore, the internal and external factors influence decision making. Business intelligence controls how to receive and share internal data better, and competitive intelligence observes the environment and people and helps the organization be readier to appear in the market. Still, if a food strategy and a suitable design based on business and competitive intelligences exist but administrations do not implement them correctly or they do not match the context, the odds are low for success. However, it improves the ability of strategic decision making in the organization and increases the possibility to add value to synthesize knowledge management, business and competitive intelligences, and to achieve the best models using strategic intelligence.

To do things successfully is intelligence, while wisdom is to do things successfully and thinking of the results for oneself and for other people. The two structures of intelligence and wisdom have overlap and while it is not enough, intelligence is the necessary condition for 
success. Empirical studies suggest that a wise person is different from an intelligent person. Reports mention the relation between wisdom and intelligence, but it is not clear what type of components wisdom and intelligence have, or what the nature of this relation is, or what the kinds of intelligence are. There is not an agreement how to define wisdom (Moberg, 2001), and the fact that strategic management with a base of strategic intelligence has taken an important role in organizations, the question is the relationship between organizational wisdom and strategic intelligence. Research is needed to properly comprehend the two of them.

When the Iranian government realized higher education was needed in the fields of actual professions, they opened the University of Applied Science and Technology and their purpose was correcting the structure of work force in the country, filling the time gaps after 8 years of war and also economical siege. The administration team controls the Universities of Applied Science and Technology in the country, and tries to create harmony between them and the different parts of economy and industry by managing the existing capacities and resources and according the different scientific applied higher education centers (Pourdjam et al, 2007). But the extent to which this university has been successful in achieving its goal is an important question. There have been debates on the issues of the mismatch of the trainings of this university as a training-base university, its inclination to the style of theoretical universities, training students in higher education levels but yet with a theoretical nature, the absence of applied chief executive staff, and inharmonic major and the minor parts of the system (Pourdjam, 2004).

Organizational intelligence is important because it is mutually related to the dynamism in the organization. Focusing on organizational intelligence in the learning organization, the strategy of organizational learning can create a ground for more accuracy and the concentration of different activities. On the other side, organizational wisdom refers to the values of wisdom in the organization environment and the reliability of its components in the structural framework of the environment. Scholars like Sternberg (1998) believe that the situational context is one influential element in wisdom. To improve any educational system namely the University of Applied Science and Technology, one should start by identifying its present state; and in this system, the multiple-face management definitely requires more attention and accuracy in the management and administration. Also, defining the strategies of the University of Applied Science and Technology that come from organizational intelligence is complicated. So, to solve the problem, it is helpful to know the environment and the research population in the domain of organizational wisdom and strategic intelligence. Although organizational wisdom and strategic intelligence and their relationships are important in universities, the researchers could not find a study in the existing literature that had examined these constructs. The studies that are related to the components of the present study in a way, although important in their own place, were diverge and unable to unite in one field which is because of the theoretical nature of the variables. This very reason emphasizes the necessity of conducting the present study and the researchers tried to create convergence and to discover their relationships by further clarifying the aspects and the elements of the variables of the study. 


\section{Methodology}

The most common method of proposing research questions was used in this study, which is the question form (Borg \& Gall, 1989). Based on Tashakkori and Teddlie (2010) 's typology measures for research designs, considering the measure of the number of approaches used in this study, it is a compound study; considering the measure of the number of phases, multiple phase; considering the measure of the type of implementation method, uninterrupted; considering the measure of implementation priority of cognitive approach, qualitative quantitative; and considering the measure of the function of the research, it is a start-over study.

The research population in the qualitative section includes the staff of the University of Isfahan as the scientific experts, and the University of Applied Science and Technology's employees with the expertise in managerial education as the applied experts. The research population in the quantitative section embodies the influential people in decision making in the University of Applied Science and Technology, including 591 participants. Sampling in the qualitative section of this study was done using the purposive multiple phase method and the chain technique to grasp the subject matter more deeply. In the quantitative section, stratified size-sensitive sampling was used with random selection. The size of each category in the whole population was taken into consideration and sampling was systematic based on the register.

A researcher-made questionnaire was utilized to study the relationship of the variables including the main variables of organizational wisdom and strategic intelligence with the aspects and components mentioned in the conceptual model of the study. The items were designed in the form of multiple choice questions and a five-point Likert scale was used. In the section of organizational wisdom, a 48-item questionnaire was designed for 10 most frequent components of organizational wisdom. In the section of strategic intelligence, based on the decided model of the study, a questionnaire of 60 items was made in three parts. In the knowledge management factor, the researchers benefited mostly from the content of the questionnaire of Fong and Choi (2009), in the competitive intelligence factor, the content of the questionnaire of Dorgy (2011), and in business intelligence factor, the content of the questionnaire of Schwartz et al (2009). The prepared questionnaire had 5 criteria in the knowledge management part, 8 criteria in the competitive intelligence part, and 7 criteria in the business intelligence part. Each criterion has 3 related questions. To test the validity of the questionnaires, content validity and construct validity were focused on and the reliability of the questionnaire was tested using the Cronbach's coefficient of determination.

In conducting factor analysis, to ensure the sufficiency of the sampling, the correlation matrix of the data not being zero and the propriety of the collected data, the Kaiser (1961) test, and to examine the homoscedasticity of the variables the Bartlette (1954) test was used. The process of factor analysis was done using the suitable statistics software i.e. Amos, and the factors of each questionnaire were separately illustrated in a model, and the measures were studied. For the validity of the questionnaires of this study, the Cronbache's Alpha coefficient of determination was applied and produced 0.93 for the questionnaire of organizational 
wisdom and 0.92 for the questionnaire of strategic intelligence.

\section{Research findings}

As the first step, sample size was large enough ( $>30)$, and according to the central limit theorem, the average of the samples was expected to have a normal distribution. Still, to confirm the normality of the data the Kolmogrov-Smirnov test was used and it showed that the data of the variables of the study have normal distribution.

To see whether there was a relationship between the 5 indicators of knowledge management, the 8 indicators of competitive intelligence and the 7 indicators of business intelligence with the total score of organizational wisdom, the Pearson correlation coefficient was used and stepwise regressions followed. The Pearson correlation coefficient and calculated significance level are illustrated in Table 1.

Table 1. the results of the correlation coefficient for the components of strategic intelligence and organizational wisdom

\begin{tabular}{|l|l|c|}
\hline $\begin{array}{c}\text { the components of strategic } \\
\text { intelligence }\end{array}$ & \multicolumn{1}{|c|}{ indicators } & $\begin{array}{c}\text { correlation coefficient with } \\
\text { organizational wisdom }\end{array}$ \\
\hline \multirow{4}{*}{ knowledge management } & knowledge acquiring & 0.57 \\
\cline { 2 - 3 } & knowledge creation & 0.57 \\
\cline { 2 - 3 } & knowledge storage & 057 \\
\cline { 2 - 3 } & knowledge distribution & 0.51 \\
\cline { 2 - 3 } & knowledge maintenance & 0.56 \\
\hline \multirow{5}{*}{ competitive intelligence } & knowing the opponent & 0.46 \\
\cline { 2 - 3 } & management style & 0.39 \\
\cline { 2 - 3 } & competition level & 0.43 \\
\cline { 2 - 3 } & knowing customers & 0.44 \\
\cline { 2 - 3 } & research in competition & 0.43 \\
\cline { 2 - 3 } & environment awareness & 0.43 \\
\cline { 2 - 3 } & market awareness & 0.49 \\
\cline { 2 - 3 } & advertisement & 0.46 \\
\hline \multirow{5}{*}{ business intelligence } & education & 0.43 \\
\cline { 2 - 3 } & emerging technologies & 0.56 \\
\cline { 2 - 3 } & organizational data safety & 0.51 \\
\cline { 2 - 3 } & informing & 0.46 \\
\cline { 2 - 3 } & data collection & 0.55 \\
\cline { 2 - 3 } & business activity & 0.57 \\
\cline { 2 - 3 } & business research & 0.46 \\
\hline
\end{tabular}

** significance at the level 0.01 level

There is a significant relationship between the total score of organizational wisdom and the indicators of the 3 components of strategic intelligence, and their correlation coefficient is positive. In other words, it can be concluded that if the indicators of the components increase, the total score of organizational wisdom increases, too. 


\subsection{Structural equations modeling}

In the model of this study, the main variables included organizational wisdom and strategic intelligence the components of each comprised 10 for organizational wisdom and 3 for the strategic intelligence. The components of strategic intelligence included 5,8 and 7 indicators respectively. The items were inserted into the model as manifest variables and thus each variable made a factor model that was measured by its items.

Organizational wisdom was shown in the form of an oval as a latent variable that was measured using the 10 components of 1 . advice and guidance, 2. experience, 3 . knowledge, 4 . age, 5. virtue, values and morality, 6. thinking and intellectual ability, 7.decision-making and judgment skills, 8. personal characteristics and social skills, 9. intelligence, and finally 10. learning skills. These components were inserted into the model, each having 3 to 6 items, measured as manifest variables and shown in the form of squares. Strategic intelligence as the other latent variable of the study which was shown in the form of an oval had 3 components of knowledge management, competitive intelligence, and business intelligence. The first component of knowledge management had 5 indicators of: knowledge acquiring, knowledge creating, knowledge storage, knowledge distribution, and knowledge maintenance. The second component of strategic intelligence namely competitive intelligence had 8 indicators of knowing the opponent, management style, competition level, knowing the customers, research in competition, knowing the environment, knowing the market, and advertisement. And the third component i.e. business intelligence had 7 indicators of education, emerging technologies, organizational information safety, informing, data collection, business activity and business research. For each indicator, 3 items as manifest variables were added to the model for measurement shown by squares (Figure 1). Considering the possibility of error in measurement, for example higher or lower data due to different causes like the answering situation, plenty of time, etc., a measurement error was shown by "e" for each variable. Also, structural error for inability of the predictor variable in determining the dependent variable was taken into consideration shown by "z" for the latent variable. After fitting the structural equations model, as Table 2 shows, the regression coefficients and the standard regression coefficients, the critical ratio and the significance level were calculated for the variables of the study. 
Table 2. regression coefficients and standard regression coefficients, critical ratio and significance level for the variables of the study

\begin{tabular}{|c|c|c|c|c|}
\hline & variables and components & $\begin{array}{l}\text { standard } \\
\text { regression } \\
\text { coefficient }\end{array}$ & $\begin{array}{c}\text { critical } \\
\text { ratio }\end{array}$ & $\begin{array}{c}\text { significance } \\
\text { level }\end{array}$ \\
\hline \multirow{10}{*}{$\begin{array}{l}\text { organizational } \\
\text { wisdom }\end{array}$} & advice and guidance & 0.54 & & \\
\hline & experience & 0.73 & 9.28 & $<0.01$ \\
\hline & knowledge & 0.58 & 8.38 & $<0.01$ \\
\hline & age & 0.26 & 3.56 & $<0.01$ \\
\hline & virtue, values and morality & 0.84 & 8.42 & $<0.01$ \\
\hline & thinking and intellectual skills & 0.92 & 8.79 & $<0.01$ \\
\hline & decision-making and judgment skills & 0.92 & 8.79 & $<0.01$ \\
\hline & personal characteristics and social skills & 0.89 & 8.67 & $<0.01$ \\
\hline & intelligence & 0.85 & 8.48 & $<0.01$ \\
\hline & learning skills & 0.86 & 8.52 & $<0.01$ \\
\hline \multirow{3}{*}{$\begin{array}{c}\text { strategic } \\
\text { intelligence }\end{array}$} & knowledge management & 0.88 & & \\
\hline & competitive intelligence & 0.88 & 17.87 & $<0.01$ \\
\hline & business intelligence & 0.91 & 18.91 & $<0.01$ \\
\hline $\begin{array}{c}\text { strategic } \\
\text { intelligence }\end{array}$ & organizational wisdom & 0.67 & 5.80 & $<0.01$ \\
\hline
\end{tabular}

The main parameter of the model is significant with the coefficient of 0.67 . The value of standard coefficient of parameters shows a significant positive relationship between the two variables of the study and between each component and its own related variable and it can be a kind of confirmation for the offered model in this study. 


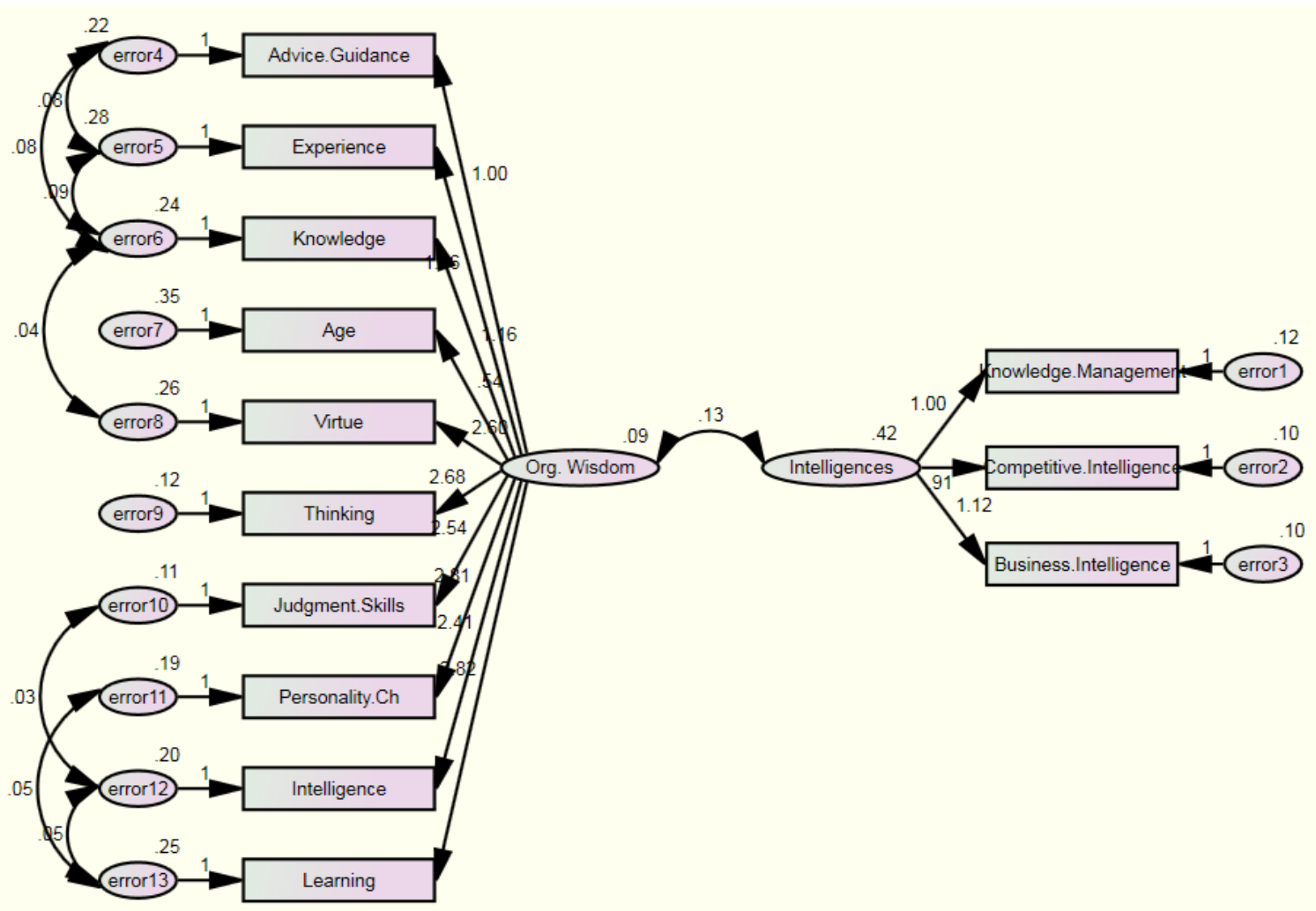

Figure 1. the complete model of path analysis of the structural equation based on regression coefficients

After determining the model, there are many methods to estimate the general goodness of fit of the model with the observed data. Several measures are used to test the fitness of the model. Generally 3 to 5 measures are enough to confirm the model. In this study, 4 types of measures were used to do so the results of which appear in Table 3. 
Table 3. the results of fitting the model

\begin{tabular}{|c|c|c|c|}
\hline the type of index & short form & acceptable domain & obtained value \\
\hline $\begin{array}{c}\text { information measure } \\
\text { index }\end{array}$ & AIC & & 180.27 \\
\cline { 2 - 4 } & BIC & & 294.09 \\
\hline \multirow{4}{*}{ comparative fit index } & CFI & $0.90-1$ & 0.98 \\
\cline { 2 - 4 } & TLI & $0.90-1$ & 0.97 \\
\cline { 2 - 4 } & IFI & $0.90-1$ & 0.98 \\
\cline { 2 - 4 } & RFI & $0.90-1$ & 0.94 \\
\hline \multirow{3}{*}{ parsimonious fit index } & NFI & $0.90-1$ & 0.95 \\
\cline { 2 - 4 } & PNFI & $0.50-1$ & 0.70 \\
\cline { 2 - 4 } & PCFI & $0.50-1$ & 0.71 \\
\hline \multirow{3}{*}{ absolute fit index } & RMSEA & $0-0.08$ & 0.06 \\
\cline { 2 - 4 } & GFI & $0.95-1$ & 0.95 \\
\cline { 2 - 4 } & AGFI & $0.98-1$ & 0.98 \\
\cline { 2 - 4 } & $\mathrm{X}^{2}$ & size sensitive & 112.28 \\
\cline { 2 - 4 } & $\mathrm{df}$ & size sensitive & 57 \\
\cline { 2 - 4 } & $\mathrm{X}^{2} / \mathrm{df}$ & size sensitive & 1.97 \\
\cline { 2 - 4 } & $\mathrm{p}$-value & size sensitive & 0.07 \\
\hline
\end{tabular}

In Table 3, the measures related to the model and their domains are reported. A significant agreement (statistically meaningful) exists for different categories of the organization over their understanding of wisdom. All the measures have acceptable scores and confirm the model. So based on the obtained values for the measures and also the obtained number for the main parameters, the research model is confirmed.

\section{Conclusion}

The findings in Table 2 show that a relationship exists between organizational wisdom and strategic intelligence with the power of $67 \%$. The findings in Table 3 about the fitness of the model, namely the absolute measure of fitness, show that the findings are generally acceptable in the related domain and the research model is supported.

The comparative fit indices including CFI, TLI, IFI, RFI, and NFI show completely acceptable scores and are all within the acceptable domain. Also, parsimonious fit indices including PNFI and PCFI had appropriate scores and RMSEA has an acceptable value. The absolute fit indices including GFI and AGFI had suitable scores, too. Thus, all the scores support the appropriateness and the goodness of fit for the research model. Furthermore, to simplify the complications, this model can be enhanced by being subdivided into subordinate sections by in future studies.

In the system of applied scientific education, because of the multi-dimensional management from the one hand, and its massive responsibilities and prophecies, there have been particular complications and challenges. To control and manage these situations, the strategies are necessary originated in high organizational intelligence and organizational wisdom in desirable level. Thus, now that a positive answer is suggested for the question concerning the possibility of studying wisdom as a structure in organizations, novel and challenging 
capacities have been created in the evolution of the world of strategic management into the world of wisdom management. Scientific applied education has more management and administration complications because education on the one hand, is recognized worldwide to be the main factor of development, and the scientific applied higher education on the other hand is the establisher of new technologies in different arenas and is also the scientific pole of training with a wealth-production basis as an effective column in higher education in Iran whose success is connected with the immense mutual conditions of the country according to its application model in the field of economy and education to enhance the profession structure. It appears to be a strategic plan to match the goals of the University of Applied Science and Technology with market needs and to change its ideals to achievable facts. In this study, the rejection of zero hypotheses suggests statistically that there is a compatible understanding and definition for organizational wisdom and also a relationship between organizational wisdom and strategic intelligence and its components. The body of the findings in this study is an indicator for the converging validity and reliability of the study with structural credit. By rating the components of organizational wisdom, this study offers a new ground to identify and define a novel approach in organizations and their human resource affairs.

This study offered and tested a means of measuring organizational wisdom. It is noteworthy that the importance of the organizational wisdom aspects which was impossible in previous studies like (Reynold 2003: 117), was made possible in this study using the factor load of each and the deductive statistic software. Since the methodology also benefited from factor analysis, there is space to suggest significant conclusions to apply the aspects of organizational wisdom in practice. The components of organizational wisdom have a basic importance in the processes of analysis and decision of the organization members and refer to high cognitive and skill-based requirements.

The present study contributed to the literature of wisdom, managerial wisdom and organizational wisdom assuming that wisdom is measurable using personal behaviors and attitudes in situational context. However, it is one of the first studies in the field of organizational wisdom and strategic intelligence in an educational organization and higher education; thus, its findings can only be an introduction in this field. This research was done to determine the relationships among the attitudes and behaviors and the wisdom of the organization, and to determine the strength of this relation. The relationship has to be studied further, though. This study was conducted assuming that the 10 most frequent aspects are the representatives of organizational wisdom, but to obtain a vaster viewpoint it is necessary to test other assumptions as well.

This study showed that different assessment studies, either in or out of the organization, can be beneficial to create a better long-term viewpoint, to enhance the management system of the university in a scientific method, and to create different universities, which are new and dynamic and are sometimes called the third generation. It seems that field research in systematic thinking frameworks are necessary and it is not enough to just think if one wants to find the present strengths and weaknesses of the quality and the quantity, how to develop the organization quality and quantity, the situation of the available resources and their 
designation, the globalization issues of higher education and universities, knowing the international experiences and other countries' successful behavior for adaptation and localization, and other things like that. Country logistics and context study for the wise choice from developmental strategies is one of the basic points of modern management to rev up the calm, joyful and hopeful organizations in skill-centered universities, and it is necessary to focus on research as the core of activities to achieve the maximum efficiency.

As a result of this study, a structure was defined for the concept of organizational wisdom and based on it, an instrument was made for measuring organizational wisdom and it can be benefited from in future studies in management wisdom and even in social communities. Based on the findings of this study, more is known about the level of organizational wisdom existing in organizations and applied scientific education on the basis of defined measuring instruments. On the other hand, as a result of this study, an instrument was made in order to measure strategic intelligence, and it can be used for other studies about strategic management, strategic intelligence of management, and even other social communities. Since the instrument made to measure strategic intelligence itself is made up of 3 other instruments including strategic intelligence, business intelligence and knowledge management, each of them can be used independently. In addition to organizational wisdom, this study provides means to measure strategic intelligence in organizations and scientific applied education management through defined measuring instrument, and based on the findings of this study the system management process and strategic management process can be designed in a new form and framework, be implemented and better results be achieved.

Enhancing and increasing the coverage of the aspects of organizational wisdom, each have several angles with complicated width and complicated relations that activities in each of them by the managers of organizations need specialized investigations. Structures like motivation and will, social and civil norms, the extent of the aspects being inherent or acquirable and the like are issues that no studies were seen to have focused on comprehend and express them in the field of organizational wisdom. Therefore, it is recommended that researchers conduct studies based on their fields of interest and the above-mentioned subject matters.

\section{References}

Bartlett, M. S. (1954). A note on the multiplying factors for various $\mathrm{X}^{2}$ approximations. Journal of the Royal Statistical Society. Series B (Methodological), 296-298.

Borg, W. R., \& Gall, M. D. (1989). Educational research: an introduction (5th Ed.) New York: Long man.

Chandler, M. J., \& Holliday, S. (1990). Wisdom in a post apocalyptic age. In R. J. Sternberg (Ed.), Wisdom: Its nature, origins, and development (121-141). Cambridge: Cambridge University Press.

Corbin, J., \& Strauss, A. (2008). Basics of qualitative research: Techniques and procedures for developing grounded theory, Sage.

DeLong, D. W. (2004). Lost knowledge: confronting the threat of an aging workforce. New 
York:

Oxford

University

Press.

http://dx.doi.org/10.1093/acprof:oso/9780195170979.001.0001

Dorgi, P. (2012). Competitive Intelligence and Marketing Intelligence. Tehran: Rasa.

Fong, P. S. W., \& Choi, S. K. Y. (2009). The processes of knowledge management in professional services firms in the construction industry: a critical assessment of both theory and practice. Journal of Knowledge Management, 13(2), 110-126. http://dx.doi.org/10.1108/13673270910942736

Jason, L. A., Reichler, A., King, C., Madsen, D., Camacho, J., \& Marchese, W. (2001). The measurement of wisdom: A preliminary effort. Journal of Community Psychology, 29(5), 585-598. http://dx.doi.org/10.1002/jcop.1037

Kaiser, H. F. (1961). A note on Guttmann's lower bound for the number of common factors.British Journal of Statistical Psychology, 14(1), 1-2. http://dx.doi.org/10.1111/j.2044-8317.1961.tb00061.x

Kramer, D. A. (1990). Conceptualizing wisdom: the primacy of affect - cognition relations. In R. J. Sternberg (Ed.), Wisdom: Its nature, origins, and development (279-313). Cambridge: Cambridge University Press.

Libowitz, J. (2011). Strategic Intelligence. Translation by Tarokh \& Hatami. Tehran: The University of Khajeh Nasir.

Moberg, D. J. (2001). Managerial wisdom. Research in Ethical Issues in Organizations, 3, 377-396. http://dx.doi.org/10.1016/s1529-2096(01)03021-8

Nafisi, A. (2001). The study of the Shortcomings of the Educational System and the Market, and Solutions. Tehran: Educational Planning and Research Organization of the Education Department.

Pourdjam, M. (2005). The internal quality assessment of the training courses in the University of Applied Science and Technology. MA thesis. Isfahan: the Islamic Azad University, Khorasgan Branch.

Pourdjam, M., Mohammadi, R. \& Gholizadeh, A. (2007). The safe approach of quality assurance in higher education administration. The Journal of Human and Social Sciences, 21(6), 13-39.

Reynolds, D. J. (2003). A study of U. S. chief executive officers managerial wisdom. A dissertation submitted to the faculty of Argosy University for the doctor of business administration. Florida: Sarasota, Argosy University.

Schwarz, E. J., Wdowiak, M. A., Almer-Jarz, D. A., \& Breitenecker, R. J. (2009). The effects of attitudes and perceived environment conditions on students' entrepreneurial intent: An Austrian perspective. Education and Training, 51(4), 272-291. http://dx.doi.org/10.1108/00400910910964566

Sternberg, R. J. (1985). Implicit theories of intelligence, creativity and wisdom. Journal of 
Personality

and

Social

Psychology, 2015, Vol. 5, No. 2

http://dx.doi.org/10.1037/0022-3514.49.3.607

Sternberg, R. J. (1990b). Wisdom: Its nature, origins, and development. Cambridge: Cambridge University Press. http://dx.doi.org/10.1017/CBO9781139173704

Sternberg, R. J. (1998). A balance theory of wisdom. Review of General Psychology, 2(4), 347-365. http://dx.doi.org/10.1037/1089-2680.2.4.347

Tack, W. L. (1986, Summer). Don't ignore seasoned managers: The case for management cycling. Sloan Management Review, 27(4), 63-70.

Tashakkori, A., \& Teddlie, C. (2010).Sage handbook of mixed methods in social \& behavioral research ( $2^{\text {nd }}$ ed.). Ca: Sage.

Unesco. (2000). Higher education in twenty- first century: vision and action world conference on higher education, Paris: final report. 